\title{
Crater, Catastrophe, Contingency: An Improbable Journey and the Human Situation: A Review of Books by Walter Alvarez
}

Barry Wood

University of Houston

Correspondence | Barry Wood, barrywood1940@yahoo.com

Citation | Wood, B. (2019) Crater, Catastrophe, Contingency: An Improbable Journey and the Human Situation: A Review of Books by Walter Alvarez. Journal of Big History, III(2); 101 - 114. DOI | http://dx.doi.org/10.22339/jbh.v3i2.3260

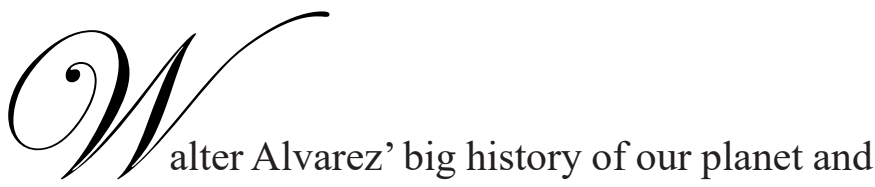
ourselves, A Most Improbable Journey (2017), begins with a 1991 expedition to Mexico with two other geologists to search for ejecta from the 110-milediameter Chicxulub crater recently found straddling the Yucatan Peninsula and Gulf of Mexico. This was a follow up episode in a decade-long - and by now well-known - story. It began when Alvarez presented his theory that a large asteroid had struck the Earth 65 million years ago, causing the extinction of the dinosaurs. His evidence was a mysterious centimeterthick layer of clay located at the Cretaceous-Tertiary (K-T) boundary in the Apennine Mountains near the Medieval town of Gubbio. The mystery, however, was less in the clay itself, which was devoid of even microfossils, than in the dramatic change in fossil evidence from the Cretaceous layers below it to the newer Tertiary layers above. After discussion among associates and considerable puzzlement, analysis showed that it contained an unusual amount of iridium, an element rare on Earth but abundant in asteroids. No visible evidence of a local asteroid strike in Europe was known, thus leaving the location a mystery for a time. Eventually this iridiumrich clay was discovered

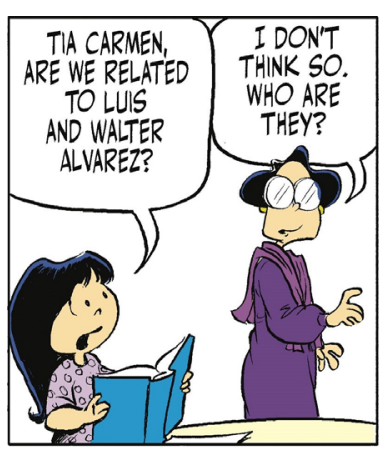
at more than 100 sites around the world, wherever the K-T boundary was exposed. This led Alvarez to conclude that a city-sized asteroid 10 to 12 miles in diameter had struck the earth somewhere, causing a catastrophic disruption of planetary climate. Since the K-T boundary corresponded with the disappearance of numerous megafaunal species, Alvarez theorized that this hitherto unknown asteroid had brought down the dinosaurs that had dominated the Earth over the previous 200 million years, along with half the world's wildlife. Following its publication in Science (1980), his theory received a lukewarm, sometimes hostile, response in the geological community until the Chicxulub Crater was discovered a decade later and dated at 65 million years. In an almost perfect followed by the discovery of evidence that confirmed it. Today the idea that an asteroid drove the dinosaurs repeated in causal conservations, and is taught to grade school children. example of how science should work, his theory was to extinction has passed into popular knowledge, been

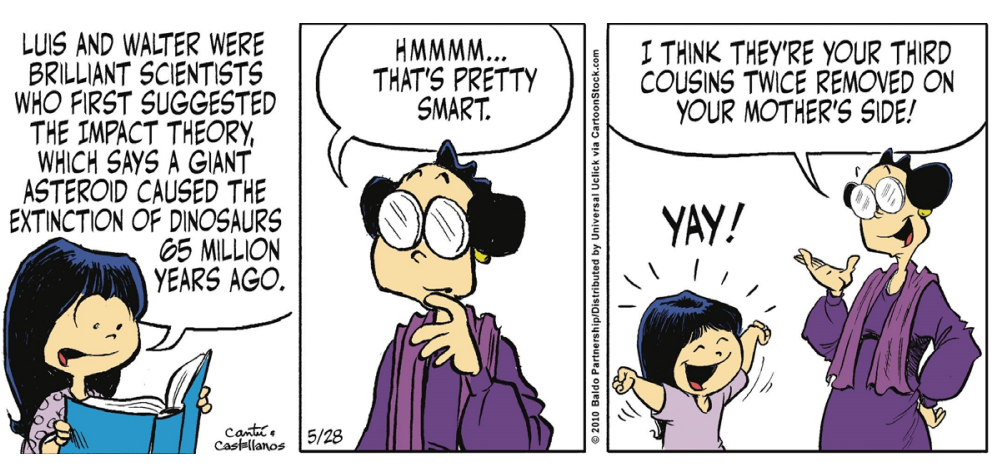

Fig. 1. Family History according to Tia Carmen. Cartoons often indicate the popularity of a scientific theory. Artists: Cantu and Castellanus. www.cartoonstock.com 


\section{A Catastrophic Impact}

The full story was set out by Alvarez in T-Rex and the Crater of Doom (1997). So why did he return in 2017 to an event that had been confirmed more than a quarter century earlier? The answer lies in the unifying theme of the "improbable journey." From this perspective, T-Rex and the Crater of Doom and A Most Improbable Journey can be seen as a single two-part presentation, rich in geological lore and illustrating a motto Alvarez uses to introduce the basics of geology and petrochronological dating: Ex libro lapidum historia mundi, "The history of the world [comes] from writings in rocks." The significance of these volumes lies in putting to rest a long standing assumption of geological change as occurring gradually and uniformly over vast time periods. Their deeper significance, especially the second volume, lies in his big history narrative with an emphasis on the theme of contingency. The Alvarez discovery shows that the existence of life, including human life as we know it, depends on events of the past sometimes forgotten, perhaps undiscoverable, and often catastrophic. The asteroid that struck Earth 65 million years ago symbolizes all such events and brings home the tenuousness of the human situation. By extension, it suggests that the possibility of life across the Universe may be due for reexamination.

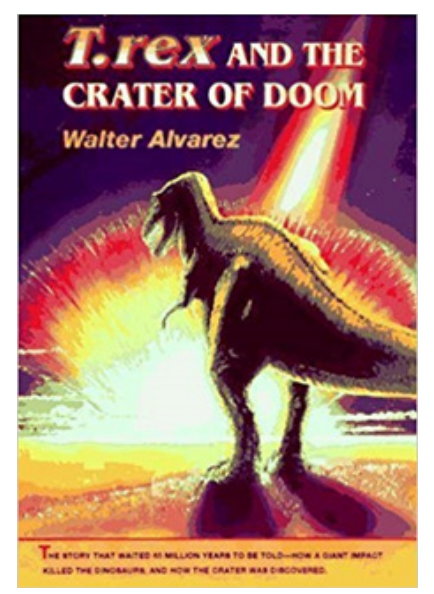

Fig. 2. T-rex and the Crater of Doom (1997) tells the story of the day an asteroid struck Earth at Chiczulub 65 million years ago, its author's 1979 discovery of asteroid fallout at the K-T boundary in the Apennines, his theory of dinosaur extinction, and the 1991 confirmation of a 65-million-year-old crater buried under nearly a mile of sediment in the Yucatan Peninsula and Gulf of Mexico.
The gradualist uniformitarian theory that prevailed through most of the twentieth century was so deeply embedded that it is worth examining its history, for therein lies the importance of the Alvarez books. The contrary theory of catastrophism that preceded it had its heyday in the late eighteenth and early nineteenth centuries, with periodic resurgences among twentieth century fundamentalists. Its foundation was the catastrophic biblical flood (Gen. 6-8) which many thinkers, even those with scientific interests, regarded as literal fact. The Flood had seemingly been established as an historical event by Bishop James Usher's dates worked out in Annals of the World (1649); his dates were printed in the margins of both Oxford and Cambridge editions of the Bible for the next 230 years and remained the starting point for geological explanation. Fossils found far above sea level were seen as evidence of a worldwide flood that had carried marine life to the heights of the world's mountains. Fossils of primitive organisms at lower levels were evidence of their inability to adapt to this catastrophic event while fossils of more advanced creatures at higher levels were evidence of their greater resilience and superior skills - in essence, their higher position in the Great Chain of Being, the prevailing model of the Universe through the Renaissance and the eighteenth century (Tillyard 1942; Lovejoy 1936). Such inventive explanations to protect biblical stories had developed through Christian history from at least Augustine's fourth century Civitas Dei (The City of God). But, as Alvarez remarks, "Geology could not become a real science until the strangle-hold of Biblical chronology was broken" $(1997,43)$.

In the late $18^{\text {th }}$ and early $19^{\text {th }}$ centuries, geologists committed to fact-based, evidence-driven science began to consider new chronologies. James Hutton (1726-1797), an explorer of the wilds of Britain and a founding member of the Edinburgh branch of the Royal Society set a new standard of geological analysis. With a general education in the classics followed by studies in chemistry and medicine, he appears to have escaped all biblical influences, as did a group of associates that 
included the mathematician John Playfair, philosopher David Hume, and economist Adam Smith. In essence, Hutton recognized a material cycle whereby erosional material flowing from mountains formed layered sedimentary rock on ocean bottoms that was subsequently uplifted to form new mountains. His theory was delivered at the first two meetings of the Royal Society (1785), then published, but his Theory of the Earth (1788) was (and still is) virtually unreadable; however, John Playfair's Illustrations of the Huttonian Theory of the Earth (1802) brought it into the clear light of day. Though the cycle was too slow to observe - and neither Hutton nor Playfair had the slightest inkling of what forces drove the cycleevidence could be observed in various geological formations. Charles Lyell (1797-1875) confessed that he did not get through Hutton's book, but early in his career he traveled with Playfair to Siccar Point - the North Sea cliff where Hutton, Playfair, and James Hall had found the proof for Hutton's theory and a vision of the past now referred to as "deep time" (Wood 2019).

Charles Lyell, the greatest geologist of the $19^{\text {th }}$ century, built on Hutton's insights, but he was keenly aware of flood fictions and fabrications that were still widely promulgated in Europe. Although he had little patience with such fabrications, he took the high road, recognizing that a more compelling narrative rather than an attack or refutation was the proper method to combatting deluge theology.

Lyell's three-volume Principles of Geology (18301832), which went through twelve editions, can be seen as a sustained repudiation of catastrophism and an unrelenting presentation of evidence for uniform gradualism. Lyell refers to catastrophes just twice: first, in a context of ancient Greek and Egyptian mythology (Principles I, 9)-hardly an idea in his view to be taken seriously; second, he introduces a discussion of volcanoes with a cautionary remark: "we are not about to advocate the general doctrine of catastrophes recurring at regular intervals" (Principles II, 160-161). He made no mention of the destruction of Pompeii by

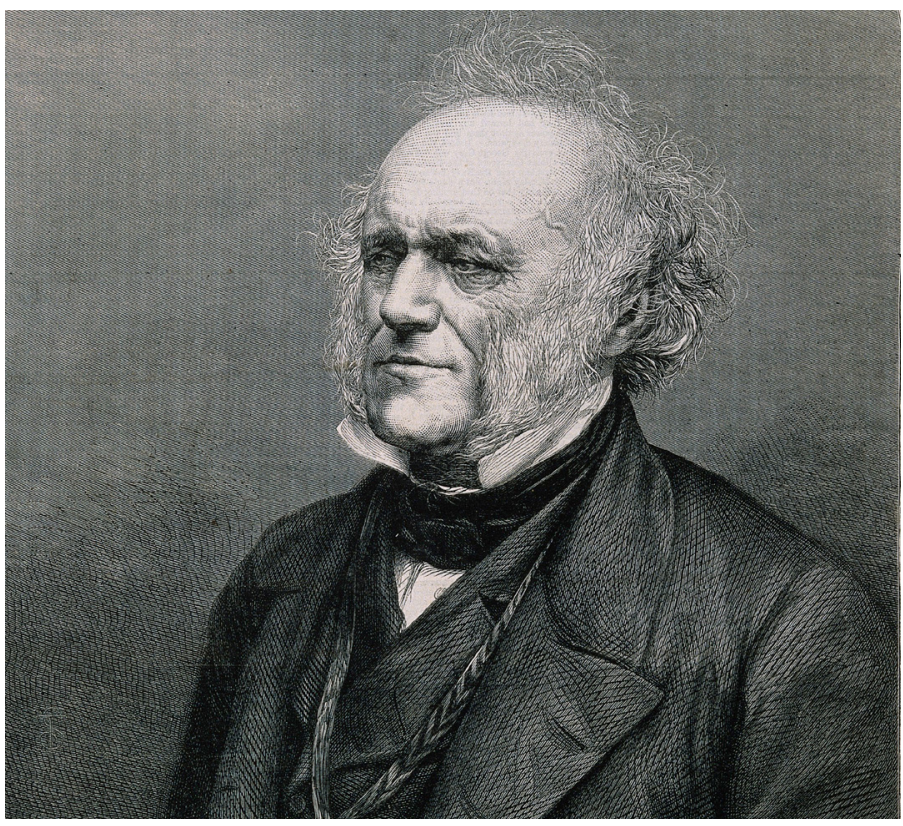

Fig. 3. Charles Lyell, the most prominent pre- $20^{\text {th }}$ century geologist, opposed catastrophism with his sustained presentation of uniform gradualism, thus exerting a century-long influence on $20^{\text {th }}$ century geologists until the Chicxulub crater verified catastrophic events as an unpredictable geological force.

Vesuvius, probably because it was a human rather than geological catastrophe. In his extensive exploration of Mount Etna (Principles III, 75-94), which had erupted a handful of times in recorded history, he noted evidence of ninety eruptions. However, his descriptive language (including quotations of poetry from Robert Schomburgk and John Milton) reduces immense overlapping lava flows to a romanticized landscape of gradualism; this was the period when English literature was dominated by Romantic poetry. His textbook, Elements of Geology, which went through six editions (1838-1865), did not mention catastrophism-not even to refute it - thus weeding out the idea for several generations of geology students. Lyell's strategy was to circle around catastrophism as if such phenomena never did and never could occur, a condemnation by silence.

So gradualism became the conventional geological wisdom of the day. As Alvarez puts it, "Uniformitarian 
gradualism provided an excellent framework for answering questions about the Earth" (1997, 59). Everywhere one turns - whether rock faces along cross-country highways or views from the rim of the Grand Canyon-hundreds of layers of sedimentary rock that can sometimes be thousands of feet thick testify to the snail-pace accumulation of silt on ancient ocean bottoms. The tilt of sedimentary layers at the Joggins Fossil Cliffs of Nova Scotia (which Lyell visited) and and the distorted rocks in the Scottish Highlands and the Alps were clearly the result of steady uplift or lateral pressure over millions of years. The sedimentary layers that folded on themselves without fracturing were proof of gradualism. Southrunning scorings on Precambrian rock surfaces in the Canadian Shield were the result of glaciers moving mere inches per year. As Alvarez remarks, "Geologists learned uniformitarianism from their teachers and found that in practice it almost always led to reliable explanations of geologic features. ... Gradualism had become a dogma" $(1997,59)$.

Against this background and Lyell's stature, it is no surprise that his gradualist uniformitarian theory of geological change persisted long into the twentieth century. It is also clear that the Alvarez theory and the subsequent confirmation that the Chicxulub impact was sufficient to drive to extinction half the life of the planet, added a dramatic new dimension, upending the prevailing geological assumptions of the twentieth century. In fact, the effects of the impact were widespread; they brought into focus a scenario that challenged the imagination. The first chapter of T-Rex and the Crater of Doom provides a narrative of the day catastrophe struck. The tell-tale iridium-rich layer Alvarez had discovered was confirmed at a cliff called Stevns Klint in Denmark, a butte in Montana called Iridium Hill, Raton Basin in Colorado and New Mexico, Caravaca, Spain, New Zealand, and other locations worldwide. These deposits of iridium-rich clay made clear that asteroid debris - a combination of the asteroid itself and Earth material from an immense impact crater-had been ejected into the upper atmosphere and subsequently circled the planet. This probably blocked out the sunlight long enough to cause a die-off of vegetation and subsequent animal extinction before the debris eventually settled to the ground.

The presentation in the second and third chapters is one of the most readable accounts of geological science of the later twentieth century beginning with what geologists look for: history written in rocks. Appreciation for their work grows with every page of this lucid narrative. Step by step Alvarez takes us through the unraveling of Earth history, their collection of further evidence in the Apennines, and the process of unwinding the mystery of the clay at the K-T boundary, all backed up by detailed notes and citations from numerous studies this event has spawned. Central to his account are the dating of fossils and different kinds of rocks, the unlocking of the past in various schedules of radioactive decay, and the chronological traces left by magnetic reversals, all of which underlie the temporalities of big history

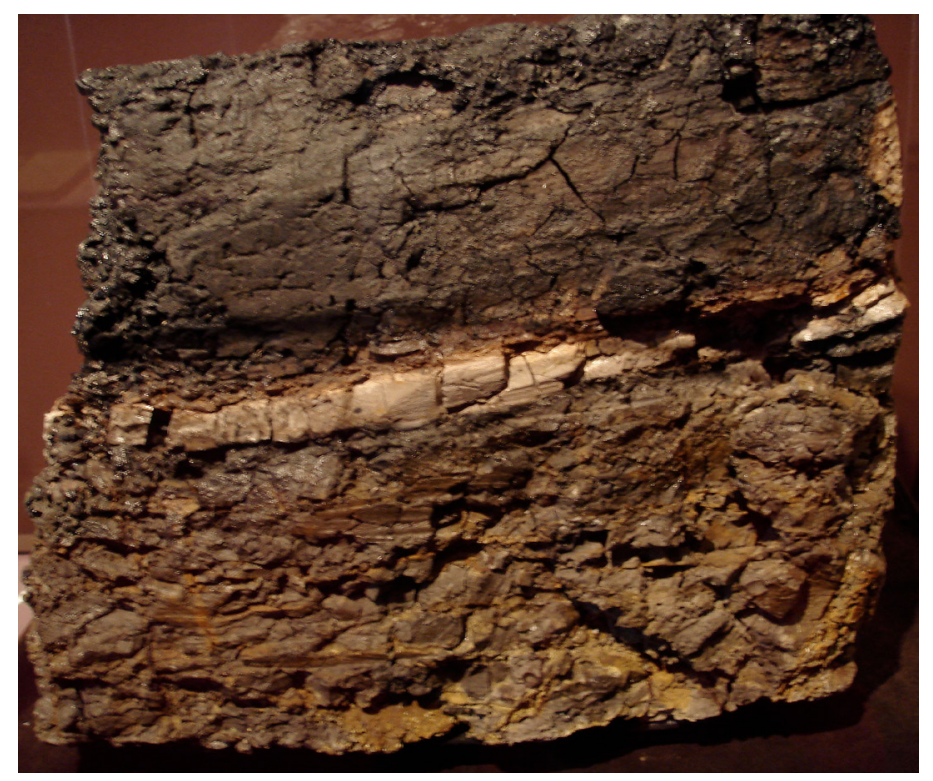

Fig. 4. A centimeter-thick layer of claystone rich in iridium, dated to 65 million years ago, marks the Cretaceous-Tertiary (K-T) boundary, separating lower rocks of the dinosaur era from the upper layers following their extinction. The layer is found worldwide; this sample is from Wyoming. https://simple.wikipedia.org/wiki/K/T_extinction_event 
(Wood 2015).

At first, Alvarez confesses, it was difficult to absorb the idea that a catastrophic event had caused a mass extinction. More than a century of gradualism was deeply inbred in the thinking of geologists through most of the twentieth century. He remarks on the 1968 orbiting of the Moon by Apollo 8 which highlighted the Moon's terrain heavily cratered from multiple asteroid hits - a recognition that suggested catastrophic events were much more common in the Solar System than gradualist geologists had so far realized-but it took more than a decade and the discovery of this catastrophic mass extinction 65 million years ago to adjust long-held assumptions. It took the discovery of the Chicxulub crater and its definitive dating to establish catastrophism as a recognizable though

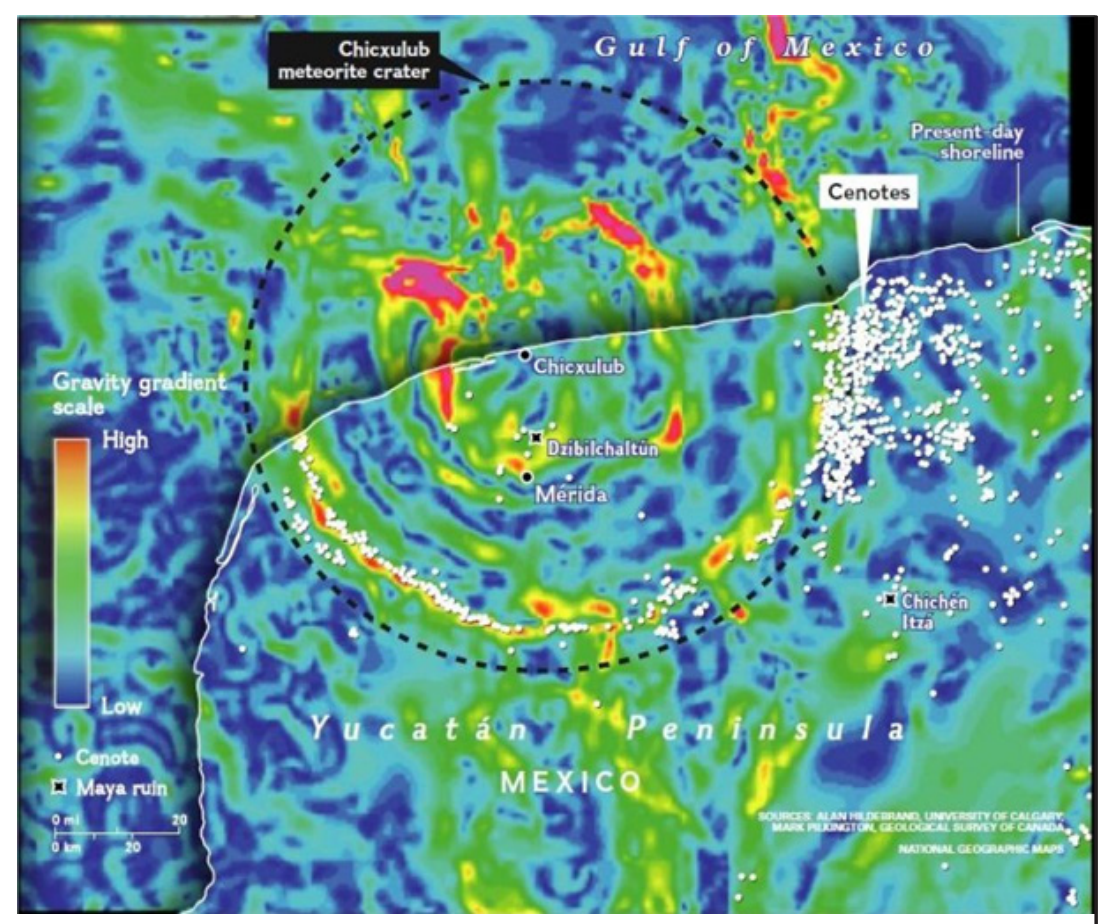

Fig. 5. Chicxulub, the site of the asteroid impact, is near the coast of the Yucatan Peninsula, indicated by the shadowed white line. Buried below hundreds of feet of silt, the 110-mile-diameter crater is here visible as a gravity anomaly. Surface evidence includes numerous cenotes - water-filled sinkholes - many of which are associated with the gravity-gradiant perimeter. Cenotes are here added to the gravitygradient map by Alan Hildebrand, Geological Survey of Canada.
The later expedition to Mexico described at the beginning of A Most Improbable Journey provides more details of the search for evidence of how the Chicxulub catastrophe had unfolded along with notes, explanations, and citations to a growing list of geological studies. It was soon clear that a massive tsunami hundreds of meters in height had rolled ashore in Cuba, Mexico, and Texas leaving behind thick deposits of sand and gravel. Shocked quartz ejected from the impact was found at 30 sites worldwide. In addition, dateable glasslike impact "spherules" were found in Alberta, Italy, Mexico, Spain, and another 65 sites around the world. "The sperules," Alvarez writes, "were formed from droplets of rock that had been melted by the heat of the impact, were ejected from the impact crater, left Earth's atmosphere and traveled long distances in ballistic free fall before reentering the Earth's atmosphere and falling back to Earth" $(2017,6)$.

Locating the crater provided proof that an impact had occurred; the global distribution of debris completed the picture of a truly catastrophic event sufficient to cause a massive die-off of species already evident in the fossil record. As Alvarez puts it, "Chicxulub marked a watershed. With the KT crater found at last, the kind of hard-core uniformitarianism which automatically rejects all inferences of catastrophic events was dead. Though no serious scientist doubts that most Earth change is gradual, geologists are now free to explore the occasional catastrophic events which have punctuated Earth history" $(1997,129)$.

\section{Earth Sorts Things Out}

Alvarez takes up his big history story in the next eight chapters, summarized in the sequence now basic to the big history 


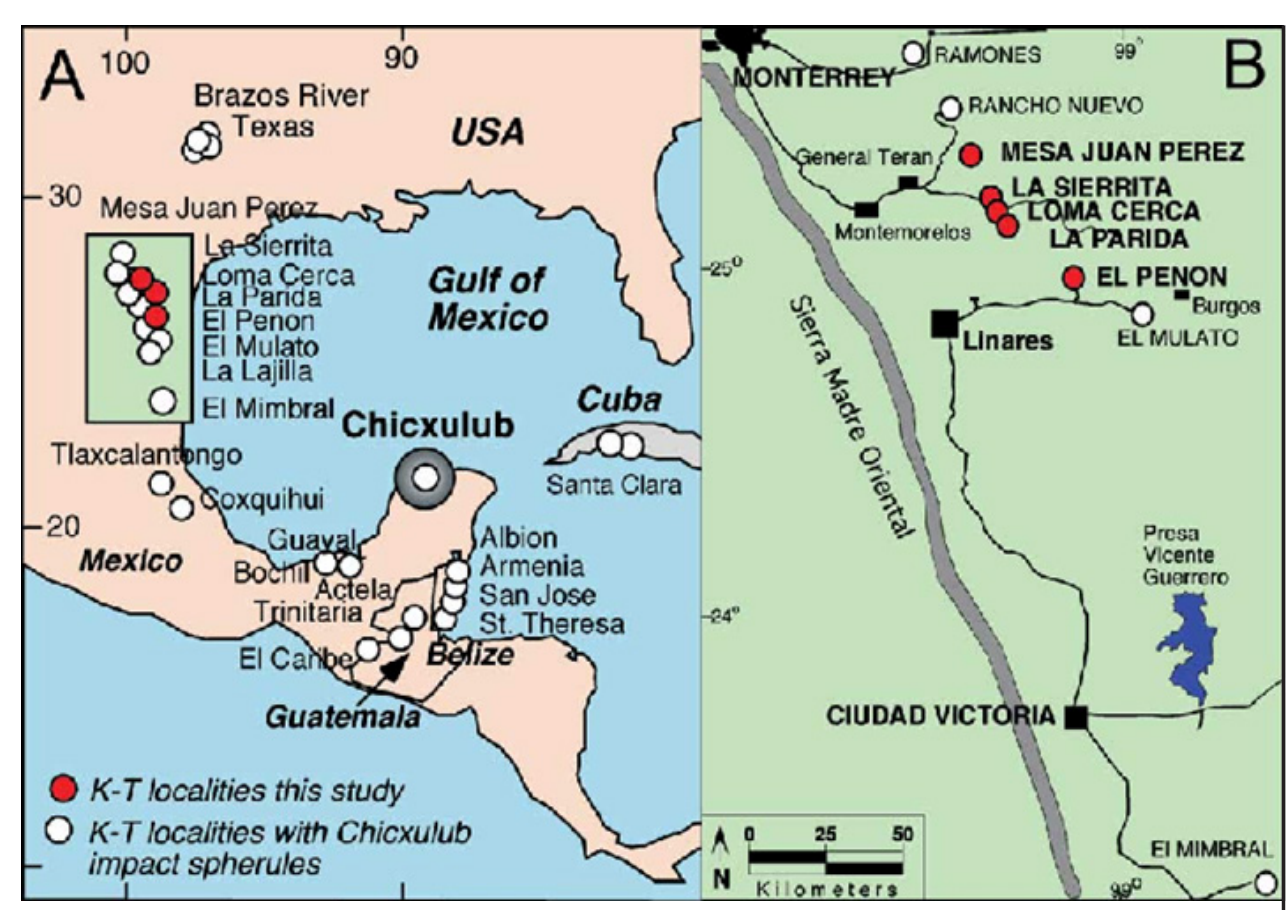

Fig. 6. Impact spherules from the Chicxulub impact have been found worldwide, with considerable concentration around the Gulf of Mexico (A), the Brazos River Valley of Texas, and multiple locations in northeast Mexico (B) where widespread evidence of a 50 to 150 meter (165 to 480 foot) tsunami has been located. narrative: Cosmos, Earth, Life, and Humanity. Since he is a geologist, it is not surprising to find that half of these (Chapters 3 to 6) are devoted to Earth narratives. Here he begins exploration of one of his most important ideas: Earth concentrates resources, thus laying the foundation for both the rise of Life and Humanity's innovations. When the Solar System began to form 4.6 billion years ago, earlier supernovas and kilonovas had scattered the full array of the ninety-two elements through space, including the dust cloud from which the Sun and planets were formed. These unsorted materials were 99\% hydrogen and helium, with all heavier elements confined to less than one percent. The formation of the planets around the giant gaseous ball of the Sun began a sorting process: light gases were blown to the far reaches of orbiting debris by solar wind, leaving behind concentrations of heavy elements in the inner Solar System. This sorting resulted in the distant gas giants-Jupiter, Saturn, Uranus, and Neptune - and the inner rocky planets-
Mercury, Venus, Earth, and Mars. The resulting Earth contained the full array of heavier elements which now make up living things - carbon, oxygen, nitrogen, calcium, and a few others-and the much heavier elements we call metals and minerals: silicon, iron, nickel, copper, aluminum, tin, platinum, and gold.

This planetary sorting was the beginning of a process Alvarez wants to highlight: the continuing work of sorting and concentrating materials in the Earth itself. Chapter 3, "Gifts from the Earth," provides a wealth of examples. During its early molten years heavier elements sink, forming Earth's iron core beneath lighter mantel materials on which buoyant surface materials of continental plates float and migrate. Within this generalized structure, additional processes are at work. The most common changes occur at the earth's surface as mountains are created, either by volcanic eruption or collision of tectonic plates. During the cooling of lava, a further sorting occurs: dense materials solidify first and sink; lighter silicon materials such as quartz $\left(\mathrm{SO}^{2}\right)$ rise to the top, resulting in a greater concentration of silicon near the Earth's surface. This has served humans from the time they first fashioned stone tools out of silicon-rich chert until today when silicon is a major component of tools of all kinds, including computer chips, aptly symbolized in the region now casually called Silicon Valley.

No matter how permanent mountains may seem, they are eventually eroded away. The Appalachians are eroded vestiges of much higher mountains from a very early tectonic collision; the Canadian Shield is the foundation remnants of some of the earliest mountains 
on Earth. Meanwhile the jagged mountains of the Alps, and Himalayas or in the process of formation from tectonic collision. But as long as any elevation remains, erosion continues its work of breaking down every kind of rock into granules of various sizes and weights. Quartz may be dissolved and precipitated from silt to form concentrated layers easily accessed. Sea creatures protect themselves with shells formed from calcite $\left(\mathrm{CaCO}^{3}\right)$ separated from seawater. Fine-grained clay washes out from quartz crystals to form separate layers of clay, later slate, while quartz crystals wash up to form the world's beaches, the source of sand, from which humans have been making glass for the past 4,000 years.

Alvarez recognizes the risk of oversimplification; brevity of description glosses over many intermediate steps. But his contribution is clear in detailing how Earth processes gradually concentrate elements in ways essential to the development of life, tool making, glass making, and advanced technology. Examples could be multiplied; as he notes, "Almost every chemical element gets enriched by Earth in one or more ways" (2017, 59). As illustration, Olga García-Moreno, with Alvarez et al (2017) have published an interesting corollary on Earth's concentration of gold, a geological process that affected modern history, especially the wealth accumulation of the Iberian Peninsula. The "gifts from the Earth" chapter thus adds an important dimension to the big history story; indeed it could qualify as a new chapter added to a seminal work published forty years ago by Erich Jantsch, also relevant for big history: The Self-Organizing Universe (1980).

\section{Earth Shapes Human History}

From a different perspective, the continents and oceans have been shapers of life and human history. The supercontinent Pangea provided the developmental stage for many amphibians and reptiles, including dinosaurs that wandered across the entire landmass before Pangea broke apart. Much
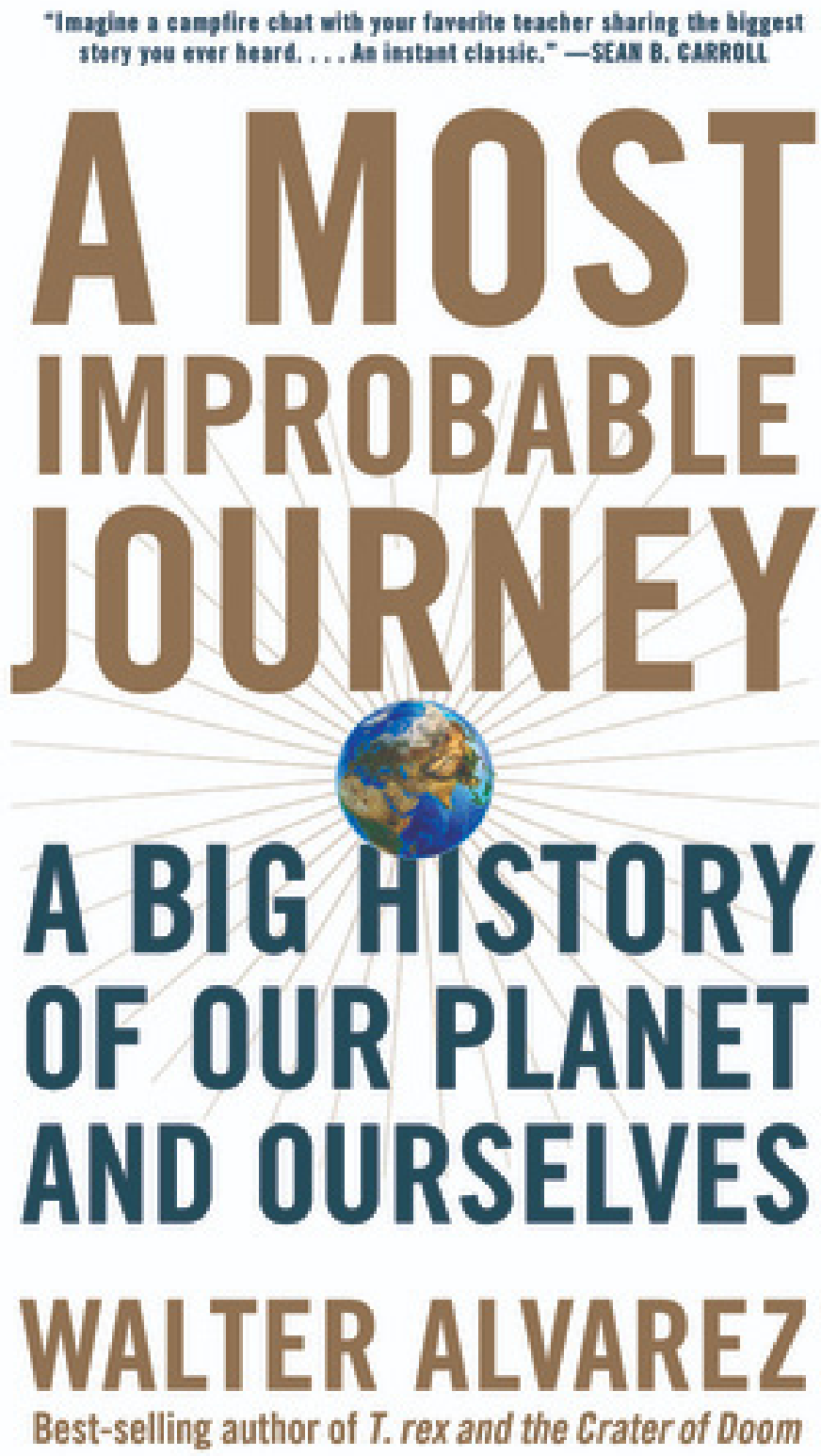

Fig. 7. Within the now well-established framework of big history, Alvarez organizes his version around a four-part narrative: Cosmos, Earth, Life, and Humanity. With the effects of the cataclysmic asteroid strike 65 million years ago as a starting point, the author opens up the theme of contingency, exploring the human situation within the improbability of human life ever evolving on Earth. 
later, the discovery of similar megafauna fossils on widely-separated continents tipped off Alfred Wegener to the idea that the continents were once joined. With this insight, he developed the first comprehensive theory of continental drift in The Origin of Continents and Oceans (1912). Continental drift theory was later folded into the theory of plate tectonics which became a kind of Copernican Revolution in geology. Alvarez remembers "an almost unbearable intellectual excitement" $(2017,69)$ in the geological community when plate tectonics emerged as the master theory of geological change.

Once the continents had drifted out of sight of each other, regional life forms developed, resulting in the great variety of birds and mammals and the quite different marsupial species confined to Australia. Much more recently, geology has ontinued to influence human history. Africa, the place where humans originated, is barely attached to the Eurasian landmass. Even then, the dominant out-of-Africa model of human migration now favors a water crossing at Bab el-Mandab (the Gate of Grief) to the southern coast of Arabia- the socalled Southern Route_ - as the first step in the peopling of the Earth. Had Eurasia been situated farther across water and out of sight, the departure from Africa would have occurred differently, much later, with a delay in cognitive enhancements sometimes attributed to environmental challenges as humans moved from tropical Africa to insular, montane, temperate, and Arctic conditions. Such geological connections between continents have shaped human history and migration in multiple ways: the relatively brief existence of Beringia and geologically recent joining of North and South America at Panama made possible a journey that took Homo sapiens on their greatest journey, from South Africa to Pantagonia.

More recently, mountain ranges have shaped human history. Of the Alps, Alvarez remarks, "they have influence or controlled great movements in history, separating language groups and religions"- - a compressed history of two millennia with various effects. The Alps confined the Italic languages-
Latin and its descendants: Italian, French, Romanian, Spanish, and Portuguese - to southern Europe; this confinement included the Roman Church which adopted Latin as its sacred language. To the north of the Alps, a quite different cluster of languages emerged-German, Danish, Norwegian, Swedish, and eventually English. Never quite in tune with the paternalist religion of the Roman Church, northern Europeans were the first to break away; Martin Luther rebelled, broke with the Catholic south, and Protestantism spread, initially gaining a solid foothold through regions north of the Alps. Equally influential have been the vast east-west range of the Himalayas. To the north, The Altaic and Sino-Tibetan languages dominated through China, Japan, and Korea, along with the religions of Confucianism, Shinto, and Taoism while the Dravidian language and a migrant branch of Indo-European dominated South Asia where the radically different religions of Hinduism and Buddhism emerged. In more recent history, Alvarez explores the way a channel at the Straits of Dover prevented a Spanish land invasion of England and a fortuitous wind scattering the Spanish Armada gave victory to England along with command of the high seas and the settlement of North America. From such seemingly inconsequential events, results of great consequence can follow.

The narrative center of A Most Improbable Journey develops around a train trip across America from New York to San Francisco. The journey structure reminds us of the earlier boating-and-trekking expedition to Oregon (1804-1806) commissioned by President Jefferson summarized in The Journals of the Lewis and Clark Expedition (1814) and The Oregon Trail (1847) by Francis Parkman describing his summer tour of the Great Plains segment-Colorado, Kansas, Nebraska and Wyoming-both rich with encounters with Native Americans. But Alvarez's east-to-west journey is perhaps most comparable to geologist John McPhee's in his four-volume, Annals of the Former World (1998), though with a presentation difference. The Alvarez narrative is strictly linear, unified by a 
four-day train trip from coast to coast; McPhee's was composed from numerous geological explorations over more than a dozen years (1978-1992), so that, as he puts it, "The structure is not linear-not a straightforward trip from New York to San Francisco on the interstate. It jumps about the country" (1998, 6). The contrast explains why so very many books of detailed analysis are desirable reads for big historians and highly relevant to big history without being big history: the final test is whether or not the book captures the big history narrative or some significant segment of the narrative.

The train route runs north up the Hudson Valley, west along the Erie Canal, and eventually the route of Interstate 80 from Chicago to the west coast. His observations are based on geological discoveries that abound across the continent. The 400-foot-high Palisades along the Hudson River tell a story of an igneous sill formed by ancient magma (2017, 9899); the elongate drumlins and north-south Finger Lakes of the State of New York are tracks left behind by glaciers that spread as far south as the Ohio and Missouri Rivers; the deep fertile plains of the Midwest are erosional material from once-towering mountains over the Canadian Shield; the salt flats across Utah are the remnants of prehistoric Lake Bonneville in northwest Utah. The most fascinating discovery is of datable zircons among the quartz crystals of Colorado Plateau sandstone originating to the east in the northern Appalachians, evidence that during the Jurassic (150 to 200 million years ago), long before today's northsouth drainage of the Mississippi watershed was established, an ancient east-to-west river flowed along an indeterminate route, following a westward slope across the Midwest that no longer exists.

Thus, virtually indestructible zircons from the Adirondack Mountains were carried more than 1,600 miles west to the Colorado Plateau, a geological province that straddles Four Corners. Alongside the seemingly permanent geological structure on his route west, Alvarez touches briefly on the not-so-permanent and highly vulnerable geology of the west coast under

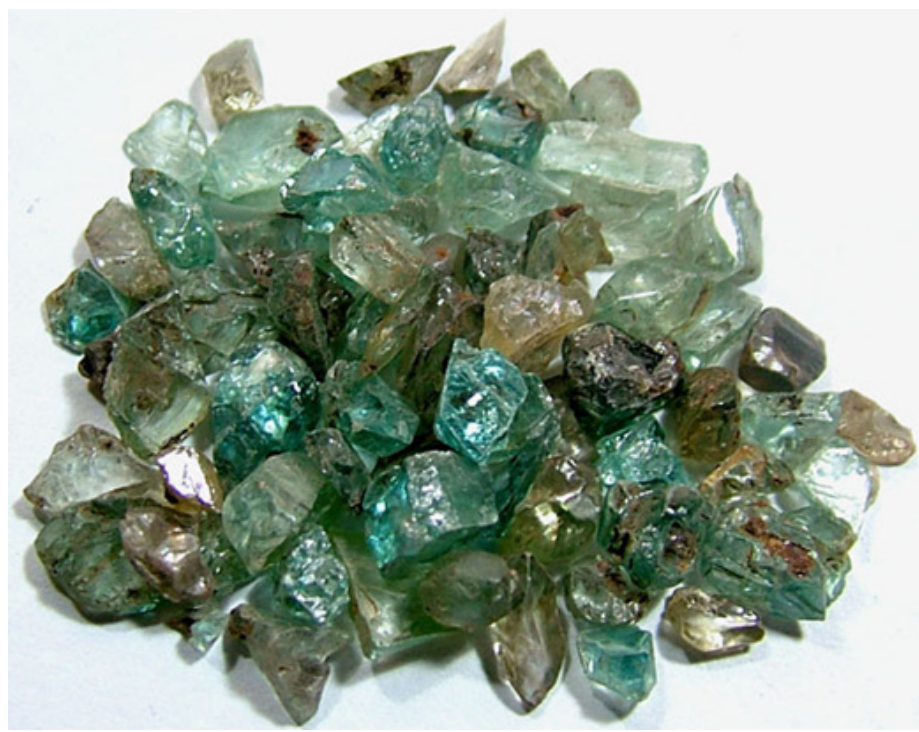

Fig. 8. Zircons are useful for dating the oldest rocks, in some cases all the way back to the Hadean Era 4+ billion years ago. Virtually indestructible, they survive intense erosion and weathering, with chemical signatures that allow geologists to trace tectonic movement or riverine transport from points of origin to locations hundreds or thousands of miles away. Source: www.gemrockauctions.com

the hand of humans. Tragic environmental destruction was caused by rapacious gold mining during the 1848-1849 gold rush along the foothills of the Sierras. There, "debris washed down by hydraulic mining overwhelmed the Sacramento River and the Central Valley" eventually "choking" parts of San Francisco Bay, leading to a ban on hydraulic mining $(2017,112$ 113).

In his treatment of the Life segment of big history, Alvarez unpacks the intersection of geology and biology with his discussion of the origin of life at hydrothermal vent locations along the same midocean ridges that are forcing apart the Earth's tectonic plates. Life in this scenario dates to the late Hadean or Early Archean eras around four billion years ago.

The subsequent a long incubation of single celled Archaea and Eubacteria was followed by the emergence of invertebrate colonies of cells, and eventually the vertebrate ancestors of modern humans. Finally, after seven-eighths of Life's history on Earth 


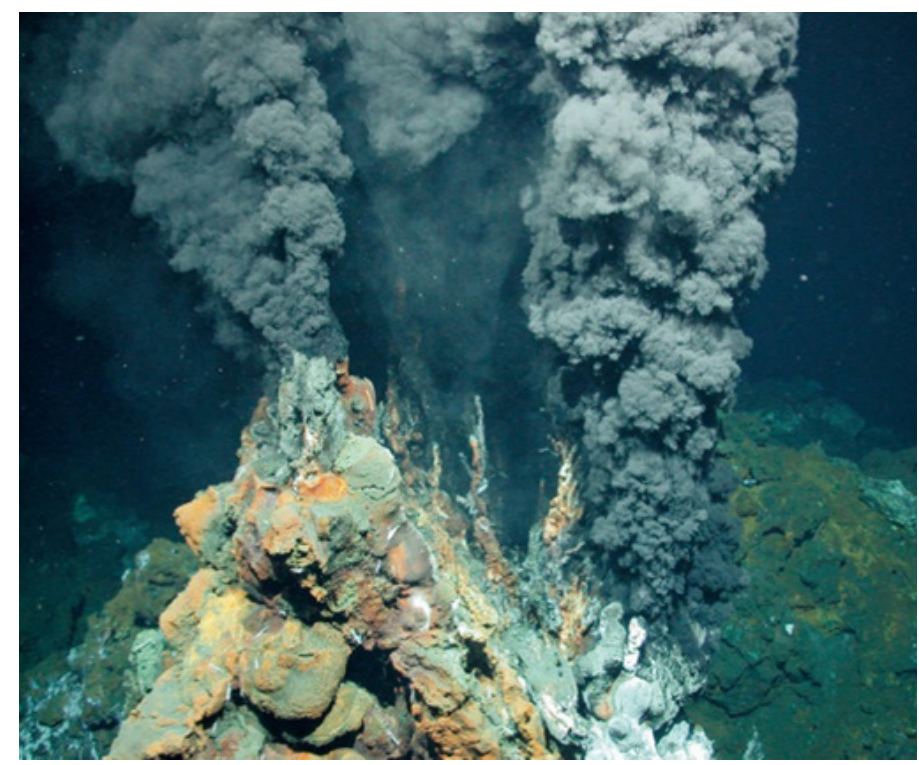

Fig. 9. Deep-sea hydrothermal vents, otherwise known as Black Smokers, are now considered likely locations for the origin of life, replacing the long-standing theory of the "warm little pond" made popular from the final paragraphs of Charles Darwin's Origin of Species (1859).

had passed, the recognizable structures, organs, and processes of vertebrates took shape. This rapid summary recounts the movement of life from sea to land, then to the end of the saurian age 65 million years ago that set the stage for mammalian and primate rise to prominence. His treatment of Humanity is equally rapid, summarizing the rise of modern humans, their acquisition of skills related to geology - the use fire, the mining of copper and tin, and tool making - while skirting developmental stages well covered in big history books by David Christian (2004), Cynthia Stokes Brown (2007), and more recently, Wendy Curtis (2013).

However, the Alvarez presentation differs from the versions by Christian, Eric Chaisson (2007), and Tyler Volk (2017). Chaisson organizes his "epic of evolution" as "seven ages of the cosmos"; Christian's "maps of time" progresses through eight "thresholds"; each of Volk's transition to a higher complexity is termed a "cosmogenesis." These paradigms suit the
Cosmos and Life phases of big history, but Alvarez sees the Earth story as a journey through time that can be discovered in continents, mountains, and oceans-above all in rocks. The present is the key to the past. Against the slow unfolding of this journey, the Chicxulub asteroid shows that regularity may be punctuated by dramatic, contingent events.

\section{Inescapable Contingency}

The emphasis through this journey is continuity: the continuous creation of seafloor at midterm ridges, the steady movement of continents, the rising of mountains an inch at a time, erosion wearing them down over millions of years. But continuity is also evident in the evolution of life and in the generations of humanity. Every human alive today is the product of parents, grandparents, and their forebears who survived to reproduce. Each human's personal existence is continuous with and depends on ancestors stretching back millions of years to earlier hominid species and eventually to our primate forebears; if any one of them had failed to reproduce, we would not exist. The conclusion makes clear Alvarez's primary theme of his "most improbable journey": "Human history is riddled with contingency, and this is part of what makes it impossible to find laws controlling history." Sometimes the minor stream of contingencies may be intensified by a dramatic, contingent event. Attempting to define a contingent event, Alvarez ventures that it "needs to be (1) rare, (2) unpredictable, and (3) significant" (2017, 181). The Chicxulub asteroid answers to all three.

The construction of the big history narrative leads us to look for regularity and pattern. Thus, we observe fine-grained temperature differences in the Cosmic Background Radiation (CBR) signifying minute density differences; then we observe that the subsequent galaxy clusters and vast empty spaces correspond to these differences in the CBR. Out of such patterns, we construct a history. But the fact is that the formation of our Sun and planets - and of every star-and-planetary system - is more far complex 
than identifying prior regions of greater density. The Sun and Earth are products of rare, unpredictable, but significant supernovas and even more rare, unpredictable, but significant kilonovas (Wood 2018), and the resulting dust clouds within which new star systems emerge. The more we examine the past, the Hadean impacts, colliding and subducting plates, volcanic eruptions, earthquakes, and random asteroid impacts, the more we realize how the present is a complex result of multiple contingent events which foreground the larger continuities.

This interaction of continuity and contingency forms the theme of A Most Improbable Journey. The book ends with a chapter called "What was the Chance of All This Happening?"- a philosophical excursion triggered by contemplating our own existence. Just what does life mean on a tilted planet swinging round a star? The number of species that have existed on Earth adds up to hundreds of millions, but not one apart from Homo sapiens reveals the potential for the higher intelligence we have achieved. If modern humans went extinct, would intelligent beings emerge again? In one of the most penetrating discussions of extinction, Jonathan Schell $(1982,114)$ remarked that it is "impossible to know what course evolution would take after human extinction, but the past record strongly suggests that the reappearance of man is not one of the possibilities. Evolution has brought forth an amazing variety of creatures, but there is no evidence that any species, once extinguished, has ever evolved again." Since Schell penned this, it has become clear that the contingencies of time, place, environment, and unpredictable events forestall evolutionary repetition.

Alvarez notes that contingencies are so numerous, particularly in the realms of Life and Humanity, that we bypass contemplating them; however "what we learn by estimating our improbability may give us insights into some of the deepest questions we can ask. This is a part of the human situation that I have never seen discussed" (2017, 193). But Alvarez chooses to discuss it by presenting it in the context of his primary discovery: "We humans exist only because of the extinction of the dinosaurs" $(2017,184)$. Our ancestors thus include primitive squirrel-or-cat-sized mammals which, in their own puzzled and confused vision, witnessed the demise of the dinosaurs and somehow avoided their fate. Once that inescapable conclusion takes root, we can see that our much earlier ancestors escaped four earlier mass extinctions 444, 375, 250, and 200 million years ago.

However, we are not simply descendants of survivors at these five critical times in the history of life; we are descendants of an unbroken lineage extending to the dawn of life itself; every one of some 35 trillion cells in our bodies has descended from an unbroken genealogy of cells through billions of creatures to the earliest chemical cluster that edged away from a black smoker. And every cell division and every mating in that long genealogy is the result of events dependent on a complex web of contingencies. We are here because every ancestor survived birth, youth, sickness, and accidental death to reach reproductive age. Finally, each mating was a union of one of many ova with one of millions of swimming sperm. Had a different sperm reached the destination in any one of millions of matings, a different genetic configuration would have resulted - a small change that would have echoed through every later generation. Again, the precise persons we are would never have come into existence.

Alvarez ends A Most Improbable Journey with a striking analogy. Counting up all the ova and sperms that enter the reproductive lottery, we see that the humans born in a single generation - around a billion $\left(10^{9}\right)$ today-represent a miniscule number compared to the total permutations and combinations $\left(10^{25}\right)$ that could have been born. To paraphrase the Alvarez analogy, fill a glass full of sand from the beach: if this represents humans actually born, all the sand on all the beaches of the world represents the astronomical number that could have been born. What is true of this generation is true of every earlier generation, each of which was the result of an almost infinite number of contingent events-metaphorically, where each 
grain of sand was on the beach when the sand was gathered. "We live our lives immersed in an ocean of contingencies ... . we can see it in the chance contingencies in each of our genealogies. Going back even one or two generations, the probability of any one of us ever being born would have been vanishingly small" (2017, 192-193).

The contingent event of the Chicxulub crater and the catastrophic extinction it brought on thus points to contingency in the broadest sense: the astronomical number of contingencies that make up life on Earth. By bracketing his big history narrative between the search for the effects of Chicxulub and the mathematics of genealogical contingencies, Alvarez opens up a new theme in the big history story, leading us to still larger questions, the deepest questions we can ask. The deepest contingency question we can ask may well be about life in the Universe because it addresses our significance or insignificance.

For half a century, the famous equation with eight plug-in variables developed by Frank Drake has led people to imagine civilizations spread across the galaxy, and by extension the Universe. With hundreds of billions of galaxies, each with hundreds of billions of stars and planets, we have tended to feel that intelligent life may be common, a virtually assured phenomenon based on statistics alone. An optimistic public has embraced this conclusion: Isaac Asimov's Foundation Trilogy (1951-1953) and the never-ending Star Trek series have nurtured it for decades. Carl Sagan's exhilaration over the idea of extraterrestrial life that permeates his Cosmos series (1980) and helped to launch the Search for Extra Terrestrial life (SETI) and the Voyager space crafts has kept the idea simmering and kept funding flowing for space probes and more powerful telescopes. But SETI has so far turned up nothing, bringing us to the question posed by Enrico Fermi, now known as the Fermi Paradox: If vast numbers of worlds harboring extraterrestrial life exist, where are they?

The Alvarez discussion of contingencies points to ultimate philosophical questions about the human situation, and perhaps the meaning of our existence. Thus, it is worth considering various conclusions about extra-terrestrial life. On the one hand, Drake himself has suggested that the numbers he and others assumed for each of the eight Drake variables are problematic because they are based on assumptions subject to preconceptions. He now considers that these assumptions were perhaps too cautionary and conservative, leading to estimates for extraterrestrial life that may have been too low. Intelligent life in the universe, he thinks, may be far more common than we have believed. Notably, however, Drake's view does not attempt to address the Fermi Paradox.

On the other hand, a recent study by Ander Sandberg et al (2018) reexamines the Drake Equation, revealing possible flaws in the paradox which arise from an extremely confident assumption of intelligent life elsewhere in the Milky Way and the Universe. In attempting to incorporate more "realistic distributions of uncertainty," they suggest "a substantial ex ante probability of there being no other intelligent life in our observable universe." Our earlier mistake may have been assuming a "high and extremely confident prior for the number of civilizations in our galaxy." This view has undoubtedly been influenced by the search for exoplanets during the last quarter century; planetary environments that might possibly harbor extremophiles could be among the thousands located, but no obvious, certain, perfect candidates for intelligent life are evident. As Frank and Sullivan (2016) write, "Recent advances in exoplanet studies provide strong constraints on all astrophysical terms in the Drake equation." Thus, Sandberg et al suggest that our "extremely confident prior" is highly tenuous against the "absence of evidence" and "current state of scientific knowledge." We have, they argue, "no reason to be highly confident that our galaxy (or observable universe) contains other civilizations." In this light, the Fermi paradox might not be a paradox at all but simply observations of an uninhabited Universe beyond our own planet.

This is not a denial of extraterrestrial life; it is 
rather a recognition of a possibility that Earth is the only place where intelligent life has appeared. Even though this is only a possibility, it is nevertheless a startling suggestion. That Earth could possibly be the only location harboring intelligent life and civilization among 350 billion galaxies, each containing as many as 100 billion planetary systems is astonishing, almost beyond comprehension. But the lesson of contingencies on Earth alerts us to the fact that contingencies must apply everywhere, and where life squeezed through multiple bottlenecks here, it would take only one impassible bottleneck on a distant world to eliminate all possibilities of intelligent life there.

Clearly this matter is unresolved and may remain so for a very long time. As long as there are solar systems left to survey - a situation that will necessarily exist until the Sun dies - an absence of evidence will prove nothing. If we do locate even a single example of intelligent life beyond Earth, the matter will be settled. Realistically, we may never be able to find it, though the more planets we discover with no demonstrable sign of intelligent life, the more the astonishing fact of our own existence will grow, and from that the significance of our own existence will also grow. If we turn out to be a common flowering everywhere, as common as space debris, we have little claim to uniqueness, but if we are without companions anywhere in the Cosmos, our significance is beyond words, understanding, and imagination, and how we got here is truly a most improbable journey.

\section{Primary References}

Alvarez, Walter. 1997. T.Rex and the Crater of Doom. Princeton, NJ: Princeton University Press. 185 pp.

Alvarez, Walter. 2017. A Most Improbable Journey: A Big History of Our Planet and Ourselves. New York: W. W. Norton \& Company. $246 \mathrm{pp}$.

\section{Secondary References}

Brown, Cynthia Stokes. 2007. Big History: From the Big Bang to the Present. New York: The New Press.

Chaisson, Eric. 2007. Epic of Evolution: Seven Ages of the Cosmos. New York: Columbia University Press.

Christian, David. 2004. Maps of Time: An Introduction to Big History. Berkeley: University of California Press.

Curtis, Wendy. 2013. The Biggest Picture: From the Big Bang to the Development of the Big Bang Theory. CreateSpace Independent Publishing Platform.

Frank, A., W. T. Sullivan III. 2016. "A New Empirical Constraint on the Prevalence of Technological Species in the Universe." Astrobiology Vol. 16, No. 5: 359-362.

García-Moreno, Olga, et al. 2017. "A Little Big History of Iberian Gold." Journal of Big History, Vol. I, No. 1: 40-58.

Hutton, James. 1788. Theory of the Earth. Sioux Falls, South Dakota: NuVision Publications, LLC.

Jantsch, Erich. 1980. The Self-Organizing Universe. Oxford: Pergamon Press.

Lovejoy, Arthur. 1936. The Great Chain of Being: A Study of the History of an Idea. Cambridge, MA: Harvard University Press.

McPhee, John. 1998. Annals of the Former World. New York: Farrer, Straus, and Giroux.

Playfair, John. 1802. Illustrations of the Huttonian Theory of the Earth. New York: Dover Publications.

Sandberg, Anders, Eric Drexler, Toby Ord. 2018. "Dissolving the Fermi Paradox." Proceedings of the Royal Society of London $A$ [Popular Physics]. 8 June: 1-16.

Schell, Jonathan. 1982. The Fate of the Earth. New York: Alfred A. Knopf. 
Tillyard, E. M. W. 1942. The Elizabethan World Picture: A Study of the Idea of Order in the Age of Shakespeare, Donne, and Milton. Oxford: Routledge.

Volk, Tyler. 2017. Quarks to Culture: How We Came to Be. New York: Columbia University Press.

Wegener, Alfred. 2011. The Origin of Continents and Oceans. New York: Dover Publications.

Wood, Barry. 2015. "Underlying Temporalities of Big History." KronoScope: Journal for the Study of Time. Vol. 15, No. 2: 157-178.

Wood, Barry. 2018. "Refueling the Magic Furnace: Kilonova 2017 Rewrites the Element Creation Story." Journal of Big History Vol. 2, No. 3: 1-16.

Wood, Barry. 2019. "Petrotemporality at Siccar Point: James Hutton's Discovery of Deep Time." Studies in Time: 50 Year ISST Anniversary Volume. Vol. 16. In press. 